\title{
Crescimento de plantas jovens de Myracrodruon urundeuva Allemão (Anacardiaceae) sob diferentes regimes hídricos ${ }^{1}$
}

\author{
Joselma Maria de Figueirôa ${ }^{2,3}$, Dilosa Carvalho de Alencar Barbosa² e Eliana Akie Simabukuro²
}

Recebido em 26/09/2002. Aceito em 28/01/2004

\begin{abstract}
RESUMO - (Crescimento de plantas jovens de Myracrodruon urundeuva Allemão (Anacardiaceae) sob diferentes regimes hídricos). Objetivou-se avaliar o crescimento das plantas jovens cultivadas em casa de vegetação submetidas a três regimes hídricos: 25,50 e $75 \%$ da capacidade de campo (cc) em duas épocas de avaliação (30 e 60 dias). As variáveis observadas foram: altura de planta, massa seca, alocação de biomassa e densidade estomática. Os três regimes hídricos não exerceram influência no comprimento da raiz. A razão de comprimento $(\mathrm{cm})$ raiz/parte aérea a $25 \% \mathrm{cc}$, foi aproximadamente de $2: 1$ e sob 50 e $75 \%$ cc manteve-se na ordem de $1: 1$. O déficit hídrico reduziu a altura das plantas sob $25 \% \mathrm{cc}$ aos 30 dias. Aos 60 dias os valores variaram de 22, 60; 22,70 e 28,76 cm em 25\%, 50\% e $75 \%$ cc, respectivamente. Houve redução significativa na área foliar, produção da massa seca sob o regime hídrico de $25 \%$ aos 30 e 60 dias, quando comparados a 50 e $75 \%$ cc. Maior alocação de biomassa foi para as raízes sob $25 \%$ aos 30 e 60 dias. M. urundeuva é hipoestomática, com estômatos do tipo anomocítico e densidade estomática variando de 372 a 524 estômatos por $\mathrm{mm}^{2}$.
\end{abstract}

Palavras-chave: aroeira, estresse hídrico, crescimento, alocação de biomassa, caatinga

\begin{abstract}
Growth of young plants of Myracrodruon urundeuva Allemão (Anacardiaceae), under water stress). The objetive was to evaluate the growth of the young plants cultivated in greenhouse conditions under three levels water stress 25,50 and $75 \%$ of the field capacity (cc) after two growth periods (30 and 60 days). The observed variables were: plant height, dry matter, biomass allocation and stomatal density. The three levels water stress, didn't exercise influence on root length. The relation between root and aerial shoot part for the treatment under $25 \% \mathrm{cc}$, was $2: 1$ approximately and under 50 and $75 \% \mathrm{cc}$, this relation was in the order of $1: 1$. The water stress reduced the height of the plants at $25 \% \mathrm{cc}$ after 30 days. After 60 days, the values found were 22,60; 22,70 and 28,76cm at 25,50 and $75 \% \mathrm{cc}$ respectively. There was significant reduction in the leaf area and production of the dry matter at $25 \% \mathrm{cc}$ after 30 and 60 days when compared at 50 and $75 \% \mathrm{cc}$. Higher root biomass allocation ocurred at $25 \% \mathrm{cc}$ after 30 and 60 days. M. urundeuva is hypostomatic, with anomocytic stomats. Stomatal density varied between 372 and 524 stomats $/ \mathrm{mm}^{2}$.
\end{abstract}

Key words: aroeira, water stress, growth, biomass allocation, caatinga

\section{Introdução}

Myracrodruon urundeuva Allemão (aroeira) é espécie florestal, pertencente à família Anacardiaceae (Santin \& Leitão Filho 1991); apresenta ampla distribuição geográfica, ocorrendo desde o México até a Argentina (Biloni 1976; FAO 1986). No Brasil, a espécie está presente em diversas formações vegetais, incluindo matas mesofíticas, sempre-verdes, sub-caducifólias e caducifólias (Ribeiro et al. 1983).

A água é o principal constituinte do vegetal, representando $50 \%$ da massa fresca nas plantas lenhosas e cerca de 80 a 95\% nas plantas herbáceas, sendo necessária para o transporte de solutos e gases, como reagente no metabolismo vegetal, na turgescência celular e na abertura dos estômatos. É, portanto, responsável pela forma e estrutura dos órgãos e essencial para o crescimento (Larcher 2000). O crescimento das plantas superiores é muito sensível às condições hídricas, e a resposta é muito mais rápida ao estabelecer situação de carência hídrica comparandose a qualquer outro fator ambiental capaz de estabelecer situação de estresse, pois primordialmente a fase de alongamento celular depende da absorção de água (Taiz \& Zeiger 2002). Nas regiões áridas e semi-áridas, as condições climáticas, como a baixa precipitação total, agravada pela irregularidade das chuvas e pela reduzida disponibilidade de água nos solos, exercem grande influência na sobrevivência e adaptação das espécies vegetais neste ambiente.

As pesquisas com espécies nativas não têm tido o mesmo desenvolvimento em relação às introduzidas

\footnotetext{
Parte da Dissertação de Mestrado da primeira Autora

2 Universidade Federal de Pernambuco, Departamento de Botânica, CEP 50560-901, Av. Prof. Moraes Rego s.n., Cidade Universitária, Recife PE, Brasil

3 Autor para correspondência: joselma@plantasdonordeste.org
} 
de rápido crescimento nas diversas áreas da ciência florestal e ecossistemas do Brasil.

A plântula é a fase mais crítica no ciclo de vida da planta, cuja sobrevivência está diretamente ligada à capacidade de germinar e aprofundar rapidamente as raízes no solo, durante a estação chuvosa. Com a suspensão das chuvas, fica comprometido seu estabelecimento. Informações disponíveis sobre o crescimento inicial de espécies lenhosas ocorrentes na caatinga são escassas. Sobre este assunto podem ser citadas relevantes pesquisas realizadas por Tigre (1968), Barbosa (1991), Barbosa \& Prado (1991), Barros \& Barbosa (1995), Silva \& Barbosa (2000), Barbosa et al. (2000) e merecem ser ampliadas com essências florestais desta região semi-árida do Nordeste brasileiro. Esta região é carente de política efetiva de reflorestamento, pois há décadas que o homem vem explorando a caatinga indiscriminadamente e informações biológicas sobre as essências florestais são importantes para o manejo adequado na região.

Este estudo teve por objetivo determinar quantitativamente o crescimento inicial através do alongamento, peso da massa da matéria seca, alocação de biomassa e densidade estomática de plantas jovens de $M$. urundeuva sob diferentes regimes hídricos em casa de vegetação. Informações dessa natureza são importantes para a produção de mudas para o plantio em campo das essências florestais, visando fornecer subsídios para implementar programas de florestamento e reflorestamento com as espécies do ecossistema caatinga.

\section{Material e métodos}

Os frutos da aroeira foram coletados em novembro/2000, no auge da frutificação, diretamente de plantas adultas de uma mesma população natural, durante a estação seca, na Fazenda Brejo, localizada em área de caatinga, na Bacia do Rio São Francisco, próxima à Hidrelétrica Xingó $\left(09^{\circ} 30^{\prime}-10^{\circ} 00^{\prime} \mathrm{S}\right.$ e $\left.37^{\circ} 30^{\prime}-38^{\circ} 00^{\prime} \mathrm{W}\right)$, Município de Canindé de São Francisco, SE.

O material botânico foi coletado e depositado no herbário UFP da Universidade Federal de Pernambuco (UFPE), registrado sob o número 28.345. Os experimentos de crescimento foram conduzidos em casa de vegetação do Departamento de Botânica da UFPE, no período de janeiro a abril/2001.

Após a coleta, as unidades de dispersão foram levadas ao laboratório de Fisiologia Vegetal da UFPE, para limpeza manual e secagem em temperatura ambiente. Em seguida foram acondicionadas em sacos de algodão e armazenadas em câmara fria e seca $\left(15^{\circ} \mathrm{C}\right.$ e $40 \%$ UR) por período de 30 dias.

Foram selecionadas 400 unidades de dispersão, tendo como critério o tamanho (diâmetro em torno de $0,5 \mathrm{~cm})$ e colocadas para germinar em bandejas plásticas de $30 \times 45 \times 7 \mathrm{~cm}$, contendo uma camada de $4 \mathrm{~cm}$ de altura de areia lavada e esterilizada em estufa por 120 minutos na temperatura de $200 \pm 1{ }^{\circ} \mathrm{C}$. Onze dias após a germinação, selecionaram-se 72 plântulas com altura média do epicótilo de $2,15 \mathrm{~cm}$, apresentando o primeiro par de folhas e com raízes em média de $2,93 \mathrm{~cm}$ compr. Posteriormente, foram transplantadas para 24 sacos de polietileno de cor preta, com diâmetro de $22 \mathrm{~cm}$ e capacidade para o volume de cinco litros, preenchidos com solo do local de coleta das unidades de dispersão. Este solo apresentou textura franco arenosa, fertilidade alta, com as seguintes propriedades $\mathrm{pH}=6,94$; $\mathrm{Na}^{+}=0,30 \mathrm{cmolc} \cdot \mathrm{dm}^{-3} ; \mathrm{K}^{+}=0,22 \mathrm{cmolc} \cdot \mathrm{dm}^{-3}$; $\mathrm{Ca}^{++}=18,0 \mathrm{cmolc} \cdot \mathrm{dm}^{-3} ; \mathrm{Mg}^{++}=5,80 \mathrm{cmolc} \cdot \mathrm{dm}^{-3} \mathrm{e}$ $\mathrm{P}=114 \mathrm{mg} \cdot \mathrm{dm}^{-3}$. O solo foi seco ao ar livre, passado em peneira de $2 \mathrm{~mm}$ de malha e a capacidade de campo (cc) foi determinada adotando-se o conteúdo de água retida pelo solo após saturação e drenagem natural, até cessar o escoamento (Souza et al. 2000). Para minimizar a evaporação do solo, o mesmo foi coberto com uma camada de bolas de isopor $( \pm 8 \mathrm{~cm}$ de espessura). A distribuição das plântulas na bancada da casa de vegetação foi inteiramente casualizada. Após 30 dias do transplante, iniciou-se a diferenciação dos tratamentos hídricos, segundo método adotado por Barros \& Barbosa (1995).

As unidades experimentais consistiram de sacos plásticos contendo três plantas cada um. Foram utilizados três tratamentos de suprimento hídrico: 25 , 50 e $75 \%$ da capacidade de campo (cc). Cada um dos tratamentos foi representado por oito unidades experimentais. Diariamente, e sempre no mesmo horário, sacos plásticos foram pesados com as respectivas plantas, em uma balança para verificação da quantidade de água consumida, e, posteriormente, adicionados os volumes necessários com a finalidade de manter a capacidade hídrica de cada tratamento.

Foram registrados na casa de vegetação, durante a realização dos experimentos, os dados de temperatura $\left({ }^{\circ} \mathrm{C}\right)$ e umidade relativa do ar $(\%)$ com um termohigrógrafo. A temperatura máxima variou de 36,6 a $37,2^{\circ} \mathrm{C}$ e a mínima, de 22,6 a $24,0^{\circ} \mathrm{C}$; a máxima UR variou de 98 a $100 \%$ e a mínima, de 46 a 52\%. 
Após 30 e 60 dias de suprimento hídrico diferenciado, quatro sacos (unidades experimentais) por tratamento, cada um contendo três plantas (subamostras), foram selecionados para realizar as medidas dos comprimentos das partes aéreas e radiculares $(\mathrm{cm})$, determinadas com auxílio de trena, da massa da matéria seca (g), do número de folhas, da área foliar $\left(\mathrm{dm}^{2}\right)$ e da densidade estomática $\left(\mathrm{mm}^{2}\right)$ nas regiões basal, mediana e apical das folhas. Para a medida do comprimento do caule, considerou-se a distância entre o colo e o ponto de inserção das folhas mais jovens.

Para a retirada das raízes, sem que estas fossem danificadas, os sacos plásticos foram rompidos verticalmente e o solo removido com jatos finos de água corrente para evitar a perda de fragmentos da raiz. Foi medido o comprimento do eixo radicular principal. Os valores de área foliar foram medidos em imagens digitalizadas em scanner de mesa, utilizando-se o programa de análise de imagens, Image Tool (UTHSCSA 1997).

Após as mensurações, as plantas, separadas em raízes, cotilédones, caules e folhas, foram submetidas à secagem em estufa a $105^{\circ} \mathrm{C}$, durante $72 \mathrm{~h}$. As determinações dos pesos da massa da matéria seca dos diferentes órgãos foram obtidas em balança analítica (AND/HR 200).

Para o estudo da densidade estomática utilizou-se o método de réplica, que consiste em cobrir as superfícies foliares com uma camada de esmalte incolor, que ao se solidificar retrata a imagem da superfície da folha. As camadas de esmalte foram colocadas nas regiões apical (A), mediana (M) e basal (B) de uma folha do $3^{\circ}$ par (do ápice para a base), completamente expandida, de coloração e aspecto uniformes, nas superfícies adaxial e abaxial (Cabral et al. 2004). Após secas, as camadas de esmalte foram removidas e montadas em laminas, em seguida levadas para microscópio binocular com aumento de 100 vezes. Utilizou-se uma área de $1 \mathrm{~mm}^{2}$, obtida com auxílio de uma ocular milimetrada. Para cada tratamento, foram realizadas contagem de estômatos em quatro folhas (uma planta por saco), três regiões e em duas superfícies, totalizando 24 contagens para cada idade estudada.

$\mathrm{O}$ delineamento experimental foi inteiramente casualizado em modelo fatorial $3 \times 2$ (três níveis de disponibilidade hídrica e dois períodos amostrais), com quatro repetições por tratamento.

Os resultados obtidos foram submetidos à análise de variância, utilizando-se o programa estatístico
SWNTIA (EMBRAPA 1996) para obtenção do teste $\mathrm{F}(\mathrm{P} \leq 0,005)$. Os dados do número de folhas foram transformados em $(\mathrm{v}+0,5)^{1 / 2}$. As médias foram comparadas pelo teste de Tukey a $5 \%$ de probabilidade (Gomes 1987).

\section{Resultados}

As unidades de dispersão de aroeira germinaram após cinco dias de semeadura, atingindo uma percentagem média de germinação de $92 \%$ do tipo epígea e com plântulas epígeo - foliácea, segundo classificação de Garwood (1996).

Alongamento radicular e da parte aérea - O comprimento da raiz principal não sofreu influência significativa nos diferentes regimes hídricos empregados, tanto aos 30 quanto aos 60 dias (Tab. 1). A razão raiz/parte aérea no regime hídrico de $25 \%$ da capacidade de campo (cc) foi de $2: 1$, diferindo significativamente dos demais tratamentos, $50 \mathrm{e}$ $75 \%$ cc, cujas razões raiz/parte aérea mantiveram-se em 1:1. A altura média das plantas aos 30 dias sob os regimes hídricos de 50 e $75 \%$ cc foram significativamente maiores que no regime de $25 \%$ cc. Aos 60 dias, os três regimes hídricos diferiram significativamente entre si, sendo o de $75 \%$ cc superior aos demais. Neste período as plantas jovens no tratamento $75 \% \mathrm{cc}$ apresentavam altura média de $28,76 \mathrm{~cm}$, caules poucos espessos.

Tabela 1. Valores médios do comprimento da raiz $(\mathrm{cm})$, altura da planta $(\mathrm{cm})$ e relação raiz/parte aérea de plantas jovens de Myracrodruon urundeuva Allemão, submetidas a três regimes hídricos e duas épocas de avaliação.

\begin{tabular}{cccc}
\hline $\begin{array}{c}\text { Tratamento } \\
(\% \text { da cc })\end{array}$ & $\begin{array}{c}\text { Compr. raiz } \\
(\mathrm{cm})\end{array}$ & $\begin{array}{c}\text { Alt. planta } \\
(\mathrm{cm})\end{array}$ & $\begin{array}{c}\text { Razão raiz/parte } \\
\text { aérea }\left(\mathrm{cm}^{-c^{-1}}\right)\end{array}$ \\
\hline & \multicolumn{3}{c}{30 dias } \\
25 & $18,21 \mathrm{a}$ & $8,59 \mathrm{~b}$ & $2,17 \mathrm{a}$ \\
50 & $19,61 \mathrm{a}$ & $14,33 \mathrm{a}$ & $1,40 \mathrm{~b}$ \\
75 & $18,41 \mathrm{a}$ & $17,04 \mathrm{a}$ & $1,13 \mathrm{~b}$ \\
Média & 18,74 & 13,32 & 1,57 \\
& & 60 dias \\
25 & $19,76 \mathrm{a}$ & $12,60 \mathrm{c}$ & $1,62 \mathrm{a}$ \\
50 & $20,32 \mathrm{a}$ & $22,70 \mathrm{~b}$ & $0,95 \mathrm{~b}$ \\
75 & $22,46 \mathrm{a}$ & $28,76 \mathrm{a}$ & $0,80 \mathrm{~b}$ \\
Média & 20,84 & 21,36 & 1,13 \\
\hline
\end{tabular}

Médias seguidas das mesmas letras na vertical não diferem significativamente entre si ao nível de $5 \%$ de probabilidade pelo teste de Tukey. 
Número médio de folhas e área foliar - Quanto ao número de folhas, os resultados obtidos aos 30 e 60 dias sob os regimes hídricos de 50 e $75 \%$ cc, não diferiram significativamente entre si; entretanto, ambos diferiram nos dois períodos em relação ao tratamento de $25 \%$ cc, sendo o número de folhas nesse tratamento o menor. A análise da área foliar mostrou padrão semelhante entre 50 e $75 \%$ cc aos 30 dias. Aos 60 dias, os três tratamentos diferiram significativamente entre si, sendo que a área foliar aumentou com o aumento da disponibilidade hídrica (Tab. 2).

Massa da matéria seca da raiz e da parte aérea Na Tabela 3 estão representados os valores médios

Tabela 2. Valores médios referentes ao número de folhas e a área foliar $\left(\mathrm{dm}^{2}\right)$ de plantas jovens de Myracrodruon urundeuva Allemão, submetidas a três regimes hídricos e duas épocas de avaliação.

\begin{tabular}{ccc}
\hline $\begin{array}{c}\text { Tratamento } \\
(\% \text { da cc })\end{array}$ & Número de folhas & $\begin{array}{c}\text { Área foliar } \\
\left(\mathrm{dm}^{2}\right)\end{array}$ \\
\hline & 30 dias \\
25 & $6,42 \mathrm{~b}$ & $0,26 \mathrm{~b}$ \\
50 & $8,00 \mathrm{a}$ & $0,81 \mathrm{a}$ \\
75 & $9,17 \mathrm{a}$ & $1,04 \mathrm{a}$ \\
Média & 7,86 & 0,70 \\
& 60 dias \\
25 & $8,25 \mathrm{~b}$ & \\
50 & $11,00 \mathrm{a}$ & $0,69 \mathrm{c}$ \\
75 & $11,67 \mathrm{a}$ & $1,80 \mathrm{~b}$ \\
Média & 10,30 & $2,68 \mathrm{a}$ \\
\hline
\end{tabular}

Médias seguidas das mesmas letras na vertical não diferem significativamente entre si, ao nível de $5 \%$ de probabilidade pelo teste de Tukey. Dados do número de folhas foram transformados em $(\mathrm{v}+0,5)^{1 / 2}$. da massa da matéria seca (g) das raízes, caules, folhas, cotilédones, parte aérea total e massa seca total. Aos 30 dias foram registradas diferenças significativas, apenas para a massa seca das folhas, refletindo a redução da parte aérea no regime hídrico de $25 \%$ cc. A partir dos 60 dias, com exceção dos cotilédones, houve diferenças significativas em todas as variáveis analisadas, obtendo-se os maiores valores de massa seca para o tratamento de $75 \%$ cc. A razão da massa seca raiz/parte aérea aos 30 dias, sob regime hídrico de $25 \%$ cc, diferiu significativamente quando comparado com os regimes hídricos de 50 e $75 \%$ cc.

Alocação de biomassa nos diferentes órgãos da planta - Aos 30 dias a alocação de biomassa para as raízes foi maior e mais rápida no tratamento em que as plantas jovens de aroeira foram submetidas aos efeitos do estresse hídrico mais severo, de $25 \% \mathrm{cc}$. Essa maior alocação deve-se ao fato da presença de maior tuberosidade na raiz principal e menor altura. Nos tratamentos de 50 e $75 \%$ cc, por outro lado, a alocação para as raízes foi gradativa dos 30 aos 60 dias (Tab. 4). Quanto ao caule, os maiores valores de alocação de biomassa foram para o tratamento de $75 \% \mathrm{cc}$ aos $30 \mathrm{e}$ 60 dias, embora não tenha ocorrido diferença significativa entre eles. Aos 30 dias os regimes de maior suprimento hídrico, 50 e $75 \%$ cc, alocaram maior biomassa para a parte aérea; no entanto, no regime de maior déficit hídrico, a alocação foi maior para o sistema radicular. Aos 60 dias, esse comportamento não se manteve, tendendo a um equilíbrio na alocação de biomassa para as raízes e para a parte aérea.

Densidade estomática - Diferenças significativas não foram observadas entre os tratamentos hídricos,

Tabela 3. Valores médios da matéria da massa seca (g) das raízes, caules, folhas, cotilédones, parte aérea total e massa da matéria seca total de plantas jovens de Myracrodruon urundeuva Allemão, submetidas a três regimes hídricos e duas épocas de avaliação.

\begin{tabular}{|c|c|c|c|c|c|c|c|}
\hline $\begin{array}{l}\text { Tratamento } \\
\text { (\% da cc) }\end{array}$ & $\begin{array}{l}\text { Raízes } \\
\text { (g) }\end{array}$ & $\begin{array}{l}\text { Caules } \\
\text { (g) }\end{array}$ & $\begin{array}{l}\text { Folhas* } \\
\text { (g) }\end{array}$ & $\begin{array}{l}\text { Cotilédones } \\
\text { (g) }\end{array}$ & $\begin{array}{l}\text { Parte aérea total } \\
\text { (g) }\end{array}$ & $\begin{array}{l}\text { Massa seca total } \\
\text { (g) }\end{array}$ & $\begin{array}{l}\text { Raiz/parte aérea } \\
\qquad\left(\mathrm{g} \cdot \mathrm{g}^{-1}\right)\end{array}$ \\
\hline \multicolumn{8}{|c|}{30 dias } \\
\hline 25 & $0,11300 \mathrm{a}$ & $0,02440 \mathrm{a}$ & $0,11385 \mathrm{~b}$ & $0,00398 \mathrm{a}$ & $0,14224 \mathrm{~b}$ & $0,25355 \mathrm{a}$ & $0,79 \mathrm{a}$ \\
\hline 50 & $0,11302 \mathrm{a}$ & $0,05664 \mathrm{a}$ & $0,45810 \mathrm{a}$ & $0,00409 \mathrm{a}$ & $0,51884 \mathrm{a}$ & $0,63186 a$ & $0,23 \mathrm{~b}$ \\
\hline 75 & $0,11869 \mathrm{a}$ & $0,07972 \mathrm{a}$ & $0,38695 \mathrm{a}$ & $0,00388 \mathrm{a}$ & $0,47035 \mathrm{a}$ & $0,58905 \mathrm{a}$ & $0,30 \mathrm{~b}$ \\
\hline \multicolumn{8}{|c|}{60 dias } \\
\hline 25 & $0,40232 \mathrm{c}$ & $0,08240 \mathrm{c}$ & $0,30571 \mathrm{c}$ & $0,00402 \mathrm{a}$ & $0,36869 \mathrm{c}$ & $0,77101 \mathrm{c}$ & $1,29 \mathrm{a}$ \\
\hline 50 & $0,80675 \mathrm{~b}$ & $0,21797 \mathrm{~b}$ & $0,69414 \mathrm{~b}$ & $0,00450 \mathrm{a}$ & $0,91661 \mathrm{~b}$ & $1,72336 \mathrm{~b}$ & $0,95 \mathrm{a}$ \\
\hline 75 & $1,20555 \mathrm{a}$ & $0,34511 \mathrm{a}$ & $1,11990 \mathrm{a}$ & $0,00462 \mathrm{a}$ & $1,46964 \mathrm{a}$ & $2,67520 \mathrm{a}$ & $0,83 \mathrm{a}$ \\
\hline
\end{tabular}

Médias seguidas das mesmas letras na vertical não diferem significativamente entre si, ao nível de 5\% de probabilidade pelo teste de Tukey. cc - capacidade de campo; g = gramas; *incluída a massa do pecíolo. 
Tabela 4. Valores percentuais (\%) de alocação de biomassa da raiz, caule, folha + cotilédone e parte aérea total das plantas jovens de Myracrodruon urundeuva Allemão cultivadas em casa de vegetação sob três regimes hídricos e duas épocas de avaliação.

\begin{tabular}{ccccc}
\hline $\begin{array}{c}\text { Tratamento } \\
(\% \text { da cc })\end{array}$ & $\begin{array}{c}\text { Raizes(1) } \\
(\%)\end{array}$ & $\begin{array}{c}\text { Caules } \\
(\%)\end{array}$ & $\begin{array}{c}\text { Folhas* }+ \\
\text { Cot. }(\%)\end{array}$ & $\begin{array}{c}\text { Parte aérea } \\
\text { total }(2)(\%)\end{array}$ \\
\hline \multicolumn{5}{c}{30 dias } \\
25 & $43,63 \mathrm{aA}$ & $9,67 \mathrm{bA}$ & $46,68 \mathrm{bA}$ & $56,36 \mathrm{bA}$ \\
50 & $18,56 \mathrm{bB}$ & $8,67 \mathrm{bB}$ & $72,76 \mathrm{aA}$ & $81,43 \mathrm{aA}$ \\
75 & $22,02 \mathrm{bB}$ & $13,27 \mathrm{aA}$ & $64,70 \mathrm{aA}$ & $77,97 \mathrm{aA}$ \\
Média & 28,07 & 10,54 & 61,38 & 71,92 \\
& & $60 \mathrm{dias}$ & & \\
25 & $51,48 \mathrm{aA}$ & $10,79 \mathrm{bA}$ & $37,71 \mathrm{aB}$ & $48,51 \mathrm{aA}$ \\
50 & $46,71 \mathrm{aA}$ & $12,43 \mathrm{abA}$ & $40,85 \mathrm{aB}$ & $53,28 \mathrm{aB}$ \\
75 & $44,30 \mathrm{aA}$ & $13,03 \mathrm{aA}$ & $42,66 \mathrm{aB}$ & $55,69 \mathrm{aB}$ \\
Média & 47,50 & 12,08 & 40,41 & 52,49 \\
\hline
\end{tabular}

Letras minúsculas comparam tratamentos dentro de cada período e letras maiúsculas comparam período dentro de cada tratamento. Médias seguidas da mesma letra (minúsculas e maiúsculas) não diferem significativamente pelo teste de Tukey $(P>0,05)$. Para efeito da análise de variância os dados foram transformados em $(\% 100)^{1 / 2}$. *incluída a massa do pecíolo.

épocas de avaliação e região das folhas, quanto ao número de estômatos, com exceção para o tratamento hídrico de $25 \%$ cc, nas regiões mediana e apical aos 60 dias (Tab. 5). As folhas são do tipo hipoestomática, ou seja, estômatos encontrados na superfície abaxial. Entretanto, foram detectados na superfície adaxial próximos a nervura central estômatos grandes e espaçados, nos três níveis de regime hídrico. Os estômatos são do tipo anomocítico, células subsidiárias assímetricas. Na espécie em estudo houve uma variação de 372 a 524 estômatos por mm².

Tabela 5. Médias dos números estomáticos nas três regiões da folha de plantas jovens de Myracrodruon urundeuva Allemão, submetidas a três regimes hídricos e duas épocas de avaliação.

\begin{tabular}{ccccc}
\hline & & \multicolumn{3}{c}{ Região da folha } \\
\cline { 3 - 5 } $\begin{array}{c}\text { Tempo } \\
\text { (dias) }\end{array}$ & $\begin{array}{c}\text { Tratamento } \\
\text { (\% da cc) }\end{array}$ & Basal & Mediana & Apical \\
\hline 30 & 25 & $399,75 \mathrm{a}$ & $443,25 \mathrm{a}$ & $410,25 \mathrm{a}$ \\
30 & 50 & $381,00 \mathrm{a}$ & $409,50 \mathrm{a}$ & $410,50 \mathrm{a}$ \\
30 & 75 & $448,75 \mathrm{a}$ & $475,50 \mathrm{a}$ & $373,25 \mathrm{a}$ \\
60 & 25 & $511,25 \mathrm{a}$ & $499,50 \mathrm{~b}$ & $372,25 \mathrm{~b}$ \\
60 & 50 & $479,00 \mathrm{a}$ & $524,25 \mathrm{a}$ & $431,75 \mathrm{a}$ \\
60 & 75 & $504,75 \mathrm{a}$ & $460,75 \mathrm{a}$ & $431,75 \mathrm{a}$ \\
\hline
\end{tabular}

Médias seguidas pela mesma letra nas linhas, para cada um dos períodos de avaliação, não diferem entre si, pelo teste de Tukey $(\mathrm{P}>0,05)$.

\section{Discussão}

Estratégias sobre o crescimento inicial das essências florestais são importantes para a produção de mudas e seu aproveitamento em programas de reflorestamento, principalmente quando se trata de espécies da caatinga, ecossistema exclusivamente brasileiro, cientificamente menos conhecido e pouco protegido.

A espécie em estudo apresentou como estratégias para o estabelecimento inicial da plântula, cotilédones foliares fotossintetizantes com características de espécies pioneiras tropicais (Vogel 1980). Vale salientar ainda a persistência dos cotilédones até os 90 dias de idade e o crescimento rápido da raiz principal, garantindo assim sua sobrevivência em seu hábitat natural. Esses aspectos foram evidenciados para outras espécies lenhosas da caatinga (Silva \& Silva 1974; Barbosa 1991; Barbosa \& Prado 1991; Barros \& Barbosa 1995; Barbosa \& Barbosa 1996; Barbosa et al. 2000; Barbosa 2003; Cabral et al. 2004). Lima (1994) registrou para plântulas de Myracrodruon urundeuva persistência dos cotilédones por 60 dias, sob condições hídricas regulares.

A razão maior no alongamento da parte radicular em relação à parte aérea apresentado pela aroeira até os 60 dias de experimento no tratamento com maior déficit hídrico $(25 \%$ cc) é considerado caráter adaptativo, comum às plantas submetidas a ambientes sujeitos a períodos de estiagem prolongados (Hsiao 1973). Vale acrescentar que nos regimes hídricos de 50 e $75 \%$ cc, essa razão se manteve de 1:1 durante a realização do experimento. Respostas semelhantes foram obtidas para as espécies lenhosas da caatinga Anadenanthera macrocarpa (Benth.) Brenan, Acacia farnesiana (L.) Willd e Schinopsis brasiliensis Engl, as duas primeiras Leguminosae e a última Anacardiaceae (Barbosa 1991; Oliveira et al. 1996; Barros \& Barbosa 1995).

A maior razão do comprimento da raiz/parte aérea no tratamento com maior déficit hídrico proporcionou maior alocação de biomassa para as raízes. Esta alocação na planta jovem não somente prioriza a absorção de água, mas também resulta em menor perda por transpiração foliar, visto que a alocação de massa para as folhas foi diminuída. Segundo Taiz \& Zeiger (2002), essa explicação pode ser atribuída ao ácido abscísico (ABA) que induz o crescimento da raiz e estimula a emergência de raízes laterais, enquanto suprime o crescimento foliar. A aplicação de ABA no sistema radicular estimula os fluxos de água e de íons, 
sugerindo que o $\mathrm{ABA}$ regula o turgor não apenas pela diminuição da transpiração, mas também pelo aumento do influxo de água para as raízes. Portanto, os efeitos do ABA sobre as raízes e as folhas causam uma redução da área foliar e um aumento da área de absorção de água das raízes, o que auxilia a planta a enfrentar as condições de seca.

A diminuição da água disponível no solo teve efeito mais acentuado na área fotossintetizante de aroeira onde foi observada redução no número de folhas por planta. O aumento ascendente na área foliar total é explicado pela boa disponibilidade de água e tal fenômeno deve-se, segundo Mott et al. (1982), à relação que existe entre o tamanho alcançado pelas folhas e a umidade do ambiente. Os autores comentaram ainda que, em ambientes úmidos, ocorrem com maior freqüência folhas grandes, enquanto em ambientes secos são produzidas folhas pequenas, contribuindo para reduzir o aquecimento do tecido foliar e a transpiração na estação mais quente. Respostas semelhantes foram obtidas para as espécies da caatinga A. macrocarpa, Parkinsonia aculeata L. e A. farnesiana (Barbosa 1991; Barbosa \& Prado 1991; Barros \& Barbosa 1995).

Segundo Fahn \& Cutler (1992), o número e a localização dos estômatos variam de acordo com a baixa disponibilidade hídrica e são mais freqüentes em folhas espessas e em plantas de habitats xéricos. Fahmy (1997) verificou em 20 espécies perenes dos desertos do Egito, que todas possuíam estômatos em grande quantidade nas duas superfícies (anfiestomáticas); a densidade na superfície superior variou de 52 a 426 estômatos $/ \mathrm{mm}^{2}$ e na inferior de 42 a 373 estômatos $/ \mathrm{mm}^{2}$. A densidade estomática de M. urundeuva assemelhou-se às plantas de regiões áridas e o número de estômatos nas folhas nos três regimes hídricos apresentou variação de 372 a 524 estômatos $/ \mathrm{mm}^{2}$ na superfície abaxial. Esse comportamento deve refletir na eficiência da transpiração da espécie na caatinga, tendo em vista que as plantas desse ecossistema apresentam movimentos estomáticos rápidos, curto período com estômatos abertos restringindo a transpiração e apresentando também transpiração cuticular baixa. Esse mecanismo fisiológico dos estômatos é muito importante para a adaptação em ambiente seco, segundo conclusões efetuadas por Ferri (1955) ao estudar o balanço hídrico de algumas espécies lenhosas da caatinga. Cabral et al. 2004 registraram menor variação (119 a 155 estômatos $/ \mathrm{mm}^{2}$ ) para Tabebuia aurea (Manso) Benth. \& Hook. F. ex. S. Moore, em regimes hídricos semelhantes, ressaltando que se trata de uma espécie ocorrente em mata ciliar da caatinga. Futuros trabalhos sobre transpiração devem considerar também o tamanho dos estômatos pois, a espécie estudada apresentou uma tendência em reduzir o tamanho dos mesmos com o aumento do déficit hídrico.

Segundo Sanford \& Cuevas (1996), há diferenças entre as florestas tropicais úmidas e decíduas quanto à distribuição de sua biomassa. Nas florestas decíduas, a maior fração de biomassa é acumulada nas raízes porque, em condições de seca, mais carbono é alocado para o sistema radicular. No caso das plantas jovens de aroeira, a estratégia de adaptação às condições adversas da caatinga foi de manter maior alocação para a massa radicular no tratamento de $25 \%$ cc e formação de tuberosidade na raiz principal. Essa tuberosidade apresenta armazenamento de água e amido, desaparecendo na fase adulta (Lima 1994). O autor encontrou essa característica em outras quatro espécies arbóreas da caatinga (PE) assim discriminadas: A. macrocarpa, Amburana cearensis (Fr. Allem.) A.C. Smith, Schinopsis brasiliensis e Schinopsis tuberosa Arruda, apenas esta última manteve a tuberosidade nas raízes laterais na fase adulta. Lima (1994) registrou ainda para essas espécies na fase de planta jovem, a presença de fibras gelatinosas na porção tuberosa, sugerindo que as mesmas poderiam estar relacionadas com a absorção de água, por tratar-se de estrutura altamente higroscópica, funcionando, portanto, como outra estratégia de adaptação de plantas jovens para sobreviverem nesse ecossistema.

Barbosa et al. (2000) trabalharam com plantas jovens de duas espécies lenhosas de Leguminosae da caatinga, de dois meses de idade e suspensão de rega durante 20 dias e verificaram diferenças na alocação de biomassa entre as espécies sem presença de tuberosidade. Parkinsonia aculeata alocou mais biomassa para o caule e Senna martiana (Benth.) Irwin \& Barneby para as folhas. Os autores justificaram a maior alocação para a parte aérea em virtude da primeira espécie ser encontrada em áreas de caatinga às margens de rios e riachos, conseqüentemente, suas raízes não sofrem muito os efeitos do déficit hídrico. A segunda espécie ocorrente em lajedos propicia maiores condições para o desenvolvimento da parte aérea em relação à radicular. Resposta semelhante foi obtida para Tabebuia aurea, outra espécie arbórea da caatinga, encontrada nas mesmas condições de P. aculeata (Cabral et al. 2004).

De acordo com os resultados aqui discutidos, as 
plantas jovens de $M$. urundeuva apresentaram características adaptativas tais como: reprodução vigorosa; alta germinabilidade sem tratamento prévio, cotilédones fotossintetizantes e persistentes; rápido crescimento da raiz principal com presença de tuberosidade e maior razão de alongamento e alocação de biomassa para as raízes nas plantas submetidas ao regime de maior déficit hídrico; folhas compostas com grande número de estômatos na região abaxial.

Quanto aos regimes hídricos aplicados, pode-se chegar à conclusão de que os melhores tratamentos para a produção de mudas foram os de 50 e $25 \%$ cc, em especial este último, haja vista a escassez de água na caatinga, possibilitando maiores chances de plantio e estabelecimento das mesmas nesse ambiente.

As pesquisas ecofisiológicas sobre a reprodução e o crescimento de essências florestais da caatinga devem ser intensificadas para melhor conhecimento dessas plantas nesse ecossistema, pois tais informações servirão também de subsídios para aproveitamento em programas de reflorestamento na região semi-árida do Nordeste brasileiro.

\section{Referências bibliográficas}

Barbosa, D.C.A. 1991. Crescimento de Anadenanthera macrocarpa (Benth.) Brenan (LeguminosaeMimosoideae). Phyton 52(1): 51-62.

Barbosa, D.C.A. \& Prado, M.C.G. 1991. Quantitative analysis of the growth of Parkinsonia aculeata (L.) in a greenhouse. Phyton 52(1):17-26.

Barbosa, D.C.A. \& Barbosa, M.C.A. 1996. Crescimento e estabelecimento de plantas. Pp. 173-177. In: E.V.S.B. Sampaio; S.J. Mayo \& M.R.V. Barbosa (eds.). Pesquisa Botânica Nordestina: Progresso e Perspectivas. Sociedade Botânica do Brasil, Seção Regional de Pernambuco, Recife.

Barbosa, D.C.A; Nogueira, R.J.M.C. \& Melo Filho, P.A. 2000. Comparative studies of growth in three species of "caatinga" submitted to water stress. Phyton 69: 45-50.

Barbosa, D.C.A. 2003. Estratégias de germinação e crescimento de espécies lenhosas da caatinga com germinação rápida. Pp. 625-656. In: I.R. Leal; M. Tabarelli \& J.M.C. Silva (eds.). Ecologia e conservação da caatinga. Ed., Universitária da UFPE, Recife.

Barros, L.M. \& Barbosa, D.C.A. 1995. Crescimento de Acasia farnesiana (L.) Willd. em casa de vegetação. Phyton 57(2): 179-191.

Biloni, J.S. 1976. Livro del árbol: essencias forestales indígenas de la Argentina de aplicación ornamental. 2. ed. Tomo II. Celulosa Argentina. Buenos Aires.

Cabral, E.L.; Barbosa, D.C.A. \& Simabukuro, E.A. 2004. Crescimento de plantas jovens de Tabebuia aurea (Manso) Benth \& Hook. F. Ex. S. Moore submetidas a estresse hídrico. Acta Botanica Brasilica 18(2): 241-251.
EMBRAPA. 1996. Núcleo Tecnológico para Informática. SWNTIA/EMBRAPA, Brasília.

Fahmy, G.M. 1997. Leaf anatomy and its relation to the ecophysiology of some non-succulent desert plants from Egypt. Journal of Arid Environments 36: 499-525.

Fahn, A. \& Cutler, D.F. 1992. Xerophytes. Gebrüder Borntraeger. Berlin, Stuttgart.

FAO. 1986. Databook on endangered tree and shrubs species and provenances. (FAO. Forestry Paper, 77), Rome.

Ferri, M.G. 1955. Contribuição ao conhecimento da ecologia do cerrado e da caatinga. Estudo comparativo da economia d'água de sua vegetação. Boletim da Faculdade de Filosofia, Ciências e Letras da Universidade de São Paulo, n. 195, Botânica 12: 1-170.

Gomes, E.P. 1987. Curso de estatística experimental. 12. ed. Nobel, Piracicaba.

Garwood, N.C. 1996. Functional morphological of tropical tree seedlings. Pp. 59-129. In: M.D. Swaine (ed.). The ecology of tropical forest tree seedlings. Man \& The Biosfere Series.

Hsiao, T.C. 1973. Plant response to water stress. Annual Review Plant Physiology 24: 519-570.

Larcher, W. 2000. Ecofisiologia vegetal. Rima, São Carlos.

Lima, R.S. 1994. Estudo morfo-anatômico do sistema radicular de cinco espécies arbóreas de uma área de caatinga do município de Alagoinha, PE. Dissertação de Mestrado. Universidade Federal Rural de Pernambuco.

Mott, K.A.; Gibson, A.C. \& O'Leary, J.W. 1982. The adaptive significance of amphistomatic leaves. Plant, Cell Environment 5: 455-460.

Oliveira, M.C.P.; Barbosa, D.C.A. \& Alves, J.L.H. 1996. Aspectos morfo-estruturais da unidade de dispersão de Schinopsis brasiliensis Engl. "baraúna" (Anacardiaceae). Boletim da Sociedade Broteriana 67: 187-197.

Ribeiro, J.F.; Sano, S.M.; Macedo J. \& Silva, J.A. 1983. Os principais tipos fitofisionômicos da região dos Cerrados. EMBRAPA/CPAC, Planaltina, DF (Boletim de Pesquisa, 21).

Sanford, R.L. \& Cuevas, E. 1996. Root growth and rhizosphere interactions in tropical forests. Pp. 268-300. In: S.S. Mulkey; R.L. Chazdon \& A.P. Smith (eds.). Tropical forest plant ecophysiology. Chapman \& Hall, New York.

Santin, D.A. \& Leitão Filho, H.F. 1991. Restabelecimento e revisão botânica do gênero Myracrodruon Freire Allemão (Anacardiaceae). Revista Brasileira de Botânica 14(2): 133-145.

Silva, A.Q. \& Silva, M.A.G.O. 1974. Observações morfológicas e fisiológicas sobre Spondias tuberosa A. Cam. Pp. 5-15. In: Anais do XXV Congresso Nacional de Botânica. Mossoró, Rio Grande do Norte.

Silva, L.M.B. \& Barbosa. D.C.A. 2000. Crescimento e sobrevivência de Anadenanthera macrocarpa (Benth.) Brenan (Leguminosae), em uma área de caatinga, Alagoinha, PE. Acta Botanica Brasilica 14(3): 251-261. 
Souza, C.C.; Oliveira, F.A.; Silva, I.F. \& Amorim Neto, M.S. 2000. Avaliação de métodos de determinação de água disponível e manejo da irrigação em terra roxa sob cultivo de algodoeiro herbáceo. Revista Brasileira de Engenharia Agrícola e Ambiental 4(3): 338-342.

Taiz, L. \& Zeiger, E. 2002. Plant Physiology. 3 ed. Sinauer Associates, Inc., Publishers.
Tigre, C.B. 1968. Silvicultura para as matas xerófilas. DNOCS, Fortaleza.

UTHSCSA. 1997. Image Tool. University of Texas Health Science Center. San Antonio, Texas.

Vogel, E.F. 1980. Seedlings of Dicotyledons. Pp. 57, 59, 86. Centre for Agriculture Publication and documentation, Wageninengen. 